\title{
"It Makes you Fly to the Moon" - Stakeholder Perceptions of Physical Activity in the School Environment
}

\author{
Jaimie M McMullen ${ }^{1 *}$, Katie Hodgin ${ }^{2}$, Jennifer M Krause ${ }^{1}$, Brian Dauenhauer ${ }^{1}$, Russell L Carson ${ }^{3}$
}

\author{
${ }^{1}$ University of Northern Colorado, USA \\ ${ }^{2}$ Alliance for a Healthier Generation, USA \\ ${ }^{3}$ PlayCore, USA \\ *Corresponding Author: jaimie.mcmullen@unco.edu
}

Citation: McMullen, J. M., Hodgin, K., Krause, J. M., Dauenhauer, B. and Carson, R. L. (2021). “It Makes you Fly to the Moon” - Stakeholder Perceptions of Physical Activity in the School Environment. European Journal of Environment and Public Health, 5(2), em0070. https://doi.org/10.21601/ejeph/9372

ARTICLE INFO

Received: 4 Sep. 2020

Accepted: 23 Oct. 2020

\begin{abstract}
Abstract. Children are not achieving recommended levels of physical activity (PA), and a comprehensive school PA program (CSPAP) has been suggested as a way to address this within the school environment (CDC, 2017). Purpose: The purpose of this study, was to explore multiple stakeholders' perceptions (i.e., students, teachers, principal) of PA in the school environment. Method: Semi-structured interviews were conducted; students in Kindergarten through grade two $(\mathrm{N}=31)$ participated in focus group interviews, while teachers $(\mathrm{N}=9)$ and the principal $(\mathrm{N}=1)$ participated in individual interviews. Data were analyzed inductively using open and axial coding (Corbin \& Strauss, 2008). Results: Teachers and the principal had favorable perceptions of PA in school, identified barriers and needed supports (teachers). Students liked PA, believed it was good for them, and wanted more PA opportunities at school. Conclusion: These results provide multi-level stakeholder support for PA promotion within the school environment; and are important to consider within the CSPAP framework.
\end{abstract}

Keywords: CSPAP, physical activity, school environment, participant perceptions

\section{INTRODUCTION}

As an environment, schools have the potential to substantially influence the healthy development of children, including their participation in a physically active lifestyle (Centers for Disease Control and Prevention [CDC], 2017; Lu and Montague, 2016). Increased physical activity (PA) is associated with both physical (U.S. Department of Health and Human Services [USDHHS], 2018) and academic benefits (Sullivan, Kuzel, Vaandering, and Chen, 2017) for children; therefore, PA promotion within the school environment is a worthwhile public health effort that is aligned with a wholechild approach to education (Weissman and Hendrick, 2013). It is recommended that children five and under are physically active throughout the day and that children aged six and over accumulate at least 60 minutes of moderate-to-vigorous PA (MVPA) daily (USDHHS, 2018). According to the Institute of Medicine (IOM; 2013), schools should provide students with opportunities to achieve 30 minutes of their recommended daily PA. However, research suggests that children tend to be sedentary for the majority of their time at school (Abbott, Straker, and Erik Mathiassen, 2013; Hnatiuk, Salmon, Hinkley, Okely, and Trost, 2014). In an effort to change this trend, a comprehensive school physical activity program (CSPAP) is recommended (CDC, 2017); a CSPAP should include quality physical education, opportunities for PA participation before, during, and after school, staff involvement, and engagement of family as well as the community (CDC, 2017).

Recent studies have considered CSPAPs within specific environmental contexts ([i.e., urban and rural]; Centeio et al., 2014b; Jones et al., 2014) and there is consensus that school environment are highly contextual which influences the extent to which PA is promoted from school-to-school. Several countries have developed whole-of-school PA initiatives that align with the goals of a CSPAP (McMullen, Ní Chróinín, Tammelin, Pogorzelska and van der Mars, 2015), and national PA plans and other policy documents have continued to acknowledge the school as a key environment for PA promotion (National Physical Activity Plan Alliance, 2016; WHO, 2012). However, there continues to be a need to educate and consider the perceptions of a variety of school stakeholders (Goc Karp, Scruggs, Brown, and Kelder, 2014). This is especially critical when considering that administrator support is key to the development of a more physically active school environment (Phelps, Calvert, Hwang, Glowacki, Carson and Castelli, 2018). 
Given that there are multiple levels of influence that operate within and around the school environment which in turn influence the operation and culture of a school, Ecological Systems Theory (Bronfenbrenner, 1977; Bronfenbrenner and Morris, 1998) is an appropriate theoretical foundation for school-based research. A Social Ecological Model of health (SEM; Emmons, 2000) evolved from Ecological Systems Theory and considers the significance of the social context among its intrapersonal, interpersonal, organizational, community, and policy levels of influence on health behavior. The SEM ideally aligns with the CSPAP conceptual framework for school PA promotion, which places the student at the center given their role as the key recipient of available PA opportunities within the school environment (Carson, Castelli, Beighle, and Erwin, 2014). With student PA participation at the epicenter, a SEMderived CSPAP framework postulates that the behaviors of other key school stakeholders, such as teachers and principals, will influence how much PA students are obtaining at school (Carson et al., 2014). Therefore, it is critical to evaluate teacher and principal perceptions of PA during school in order to increase students' likelihood of reaching recommended levels of PA (IOM, 2013). Other SEM-based research corroborates the impact of multilevel factors (e.g., child factors, school environment) on young children's sedentary behavior (Määttä, Ray, Roos, and Roos, 2016), warranting a comprehensive approach to understanding and promoting healthy behaviors in a school context. Overall, a SEM of health provides relevance for a focus on the unique perceptions of multiple school stakeholders.

Classroom teachers serve a key role in PA promotion during school time, therefore it is critical to understand their perspectives regarding the implementation of PA in their pedagogical workspaces (Ellis, Cliff, and Okely, 2018; Martin and Murtagh, 2017; Stylianou, Kulinna, and Naiman, 2016; Webster, Zarrett, Skiles-Cook, Egan, and Nesbitt, 2017). There are several commonly-reported obstacles to increasing PA within the school environment, including time/space constraints, lack of support from administration, threats to classroom control, difficulty of implementation, and low student enjoyment (Dinkel, Schaffer, Snyder, and Lee, 2017; McMullen, Martin, Jones, and Murtagh, 2016; Michael et al., 2019). Despite these and other barriers, teachers have recognized the value of movement at school and reported that students show improved focus and learning following PA (McMullen et al., 2016; Stylianou et al., 2016).

While several studies like the ones discussed above have examined teachers' perceptions regarding classroom PA integration, limited research has considered the perspectives of students - who, as the recipients of school-based PA programming, are a key stakeholder group. Elementary-aged students have expressed greater learning from active lessons due to enjoyment, social interaction with peers, and having the opportunity to do something other than sit (Martin and Murtagh, 2017; McMullen, MacPhail, and Dillon, 2019). Other studies have reported that students enjoyed and were better able to learn science (Finn and McInnis, 2014) and math (Riley et al., 2017) content when PA was incorporated into their lessons. Given that students are the recipients of school-based programs, engaging them as informants and listening to their perspectives is a logical strategy (Morse and Allensworth, 2015).

Teachers have also frequently reported that support from senior management is important for their school PA implementation (Dinkel et al., 2017; McMullen et al., 2016; Phelps et al., 2018; Routen, Johnston, Glazebrook, and Sherar, 2018) and consideration of the perceptions of administration is key given their impact on school-level decisions and culture (Lynch, 2015). The few studies that have examined administrator perspectives on wellness topics have concluded that principals tend to believe that good health is important for student learning (Allison et al., 2016; Brown and Elliott, 2015). The barriers to health promotion at school, including limited time to integrate PA, however, are often significant and decrease likelihood of implementation (Todd et al., 2015; van den Berg et al., 2017). Further, many schools are likely constrained in their ability to promote PA due to environmental factors such as lack of facilities (Phelps et al., 2018).

Evidence suggests a role for schools to provide additional PA opportunities for students, but limited research has investigated multiple stakeholders' insights regarding PA promotion in schools. A conceptual framework for CSPAPs has acknowledged the importance of both the school administration and teachers when it comes to influencing PA behaviors of school children (Carson et al., 2014). Therefore, the purpose of this study was to explore perceptions of PA in school from three key stakeholder groups - students, teachers, and the principal. We focus mostly on the "during" school component of a CSPAP - specifically considering the role of PA outside of the physical education environment, such as in the classroom. Differences and similarities between stakeholder perspectives on PA promotion during school time will be highlighted in order to provide a foundation upon which effective PA promotion programs can be developed and sustained within the school environment.

\section{METHODS}

\section{Context}

The study took place in a suburban primary school (grades Kindergarten- $2^{\text {nd }}$ grade; ages 5-8) in the Western United States, and was selected based on an established relationship between the physical education teacher and the research team. The school physical education teacher was a trained physical activity leader (PAL), and had established a wellness committee that considered the promotion of PA during the school day as one of the priorities. She had recently completed a Master's degree in Physical Education and Physical Activity Leadership and had connected with the local university in an attempt to help foster a CSPAP within her school. Participating students, teachers, and the principal from the school were interviewed to examine unique perspectives of different stakeholder groups relative to the promotion of PA during the school day and in the classroom, specifically. The students at this school were primarily Caucasian (75\%) and above the federal poverty level ( $24 \%$ of students received free or reducedprice lunch). The school day started at 8:05am and ended at 2:50pm; and the students at this school received 30-45 
Table 1. Stakeholder Participant Descriptors

\begin{tabular}{|c|c|c|c|c|}
\hline Teacher & Grade Level/ Responsibility & Overall Experience & Student Focus Group Code & Student Focus Group $N$ \\
\hline Makaylin & Kindergarten & $5+$ years & $\mathrm{K}-\mathrm{A}$ & 5 \\
\hline Meghan & $1^{\text {st }}$ grade & $5+$ years & $1-\mathrm{A}$ & 6 \\
\hline Joanne & $1^{\text {st }}$ grade & $15+$ years & $1-\mathrm{B}$ & 4 \\
\hline Nikki & $1^{\text {st }}$ grade & Less than 5 years & $\mathrm{N} / \mathrm{A}$ & N/A \\
\hline Kayla & $1^{\text {st }}$ grade & $5+$ years & $\mathrm{N} / \mathrm{A}$ & $\mathrm{N} / \mathrm{A}$ \\
\hline Candice & $2^{\text {nd }}$ grade & $30+$ years & $2-\mathrm{A}$ & 5 \\
\hline Deborah & $2^{\text {nd }}$ grade & $35+$ years & $2-B$ & 6 \\
\hline Leanne & $2^{\text {nd }}$ grade & $5+$ years & $2-\mathrm{C}$ & 5 \\
\hline Trish & Enrichment (K-2) & $20+$ years & $\mathrm{N} / \mathrm{A}$ & $\mathrm{N} / \mathrm{A}$ \\
\hline Cathie & Principal & 3 years (in current position) & $\mathrm{N} / \mathrm{A}$ & $\mathrm{N} / \mathrm{A}$ \\
\hline
\end{tabular}

minutes of physical education every third day, and 50 minutes of daily recess. At the time of this study, the school had not provided any professional development for teachers focused on PA during the school day (this was subsequently offered by members of the research team at the completion of this study). Ethical approval was provided by the Institutional Review Board (IRB) at the lead author's university.

\section{Participants}

The participants of this study included 31 students (Kindergarten, $N=5$; 1st Grade, $N=10 ; 2$ nd Grade, $N=16$ ), nine teachers (Kindergarten, $N=1 ; 1$ st Grade, $N=4$; 2nd Grade, $N=3$; enrichment, $N=1$ ), and the principal from the primary school described above. All of the participating teachers and the principal were Caucasian females. Student participants included both boys and girls from each of the participating classrooms. Additional participant descriptors can be found in Table 1.

\section{Data Collection}

Data for this study include: individual interviews with each of the teachers $(N=9)$ and the school principal $(N=1)$, as well as six student focus group interviews $(N=31)$. All interviews (both individual and focus groups) were audio-recorded and participants are identified with pseudonyms throughout this paper. The teachers and the principal provided informed consent after reviewing an information letter, and were interviewed individually at a time that was convenient for them in their classrooms/office. Two trained researchers conducted the semi-structured interviews which sought to learn the perspectives of the teachers/principal related to PA promotion during school. The use of semi-structured interviews allows the researcher to react to the responses of the participants and more closely mimics a conversation than a traditional interview (Kvale and Brinkmann, 2009).

Student focus group interviews $(N=6)$ took place during school hours, and the classroom teachers selected students from their class to participate based on their parental consent to be involved in the study. All participating teachers were asked via email to allow 4-6 students from their class to participate in the focus group; however, two teachers did not reply and the enrichment teacher was not included because she sees students from various classes throughout the day. Students $(N=31)$ were asked to verbally assent to their involvement in the interview once they were selected. Each focus group included students from the same classroom (see Table 1 for specific number of students per class). The lead author and a research assistant were present for the focus group interviews, which took place in the school conference room. A semi-structured interview guide was used to determine student perceptions of PA during school (Kvale and Brinkmann, 2009).

\section{Data Analysis and Trustworthiness}

All interviews were transcribed verbatim and each transcript was read several times by two members of the research team prior to analysis. Data were analyzed inductively using open and axial coding (Corbin and Strauss, 2008), with each of the stakeholder groups' data being analyzed separately to determine themes within that specific participant group (i.e., students, teachers, and principal). The two researchers independently analyzed the data and then met to discuss emergent themes based on initial coding. Any discrepancies were resolved, and after the identification of themes, an independent reader verified the data associated with each theme. With respect to trustworthiness, the research team had established rapport with the participants as a result of their extended presence in the school. The sample size falls well within acceptable limits for similar research (Creswell, 2013). Additionally, two independent researchers analyzed the data and employed an independent reader to verify themes. Lastly, credibility was established by ensuring that themes were established based on patterns that appeared repeatedly within the data (Corbin and Strauss, 2008).

\section{RESULTS}

The results of this study will be considered within each stakeholder group, with crossover and synthesis provided in the discussion.

\section{Stakeholder: Students}

There were three consistent themes for the students in this study: PA is good for them, they like moving, and they want more PA in school.

Physical activity is good for them. Students in this study clearly understood the benefits of PA and were able to determine that it is good for them. When asked if they think moving is good for children, all students responded favorably. A 2-C student said, "I think it's [moving] good for kids because it can get your heart pumping faster," and a 1-A student said, "It [moving] keeps your body healthy and not just sitting around all tired and stuff." Another health benefit that the students attributed to moving included getting stronger, with 
several students making comments related to strength. For example, a 1-A student said, "I was gonna [sic] say that like moving makes you stronger. Like by doing push-ups, by doing jumping jacks." Further, these two comments made by a 1-A and a 2-C student, respectively, effectively illustrated this connection - “...it [moving] makes you stronger, and it makes you fly to the moon," and "[moving] makes you grow stronger like the Hulk."

Students in this study also linked moving with learning, frequently referring to a preference to be moving rather than sitting while learning. A 1-B student said, "If you don't move, your brain gets kind of unfocused because you've been working so long, and it starts to get boring." Similarly, a 2-B student said, "Like, when I exercise it helps me learn because it gets me, my brain ready and stuff." While the vast majority of the students in this study agreed with the two students quoted above, one 2-B student stated that he preferred sitting when learning, "Sitting kind of helps me learn because then I'm sitting still and my brain can really focus because then it can figure out everything really fast."

Students like moving. The students interviewed at this school overwhelmingly described enjoying movement and PA. In fact, most students, when asked what they liked to do outside of school (before PA was discussed at all), reported that they enjoyed participating in PA. For example, a 1-A student said, "When I'm not at school, I like to go outside and ride my bike with my friends," and a 2-A student said, "I like to do yoga and then especially swimming with my sister because she's such a great swimmer and she gives me advice to swim." Other students also mentioned a variety of physical activities that they enjoy outside of school. While some referred to more sedentary play, such as video games, the vast majority referred to being active outside of school.

Further, when asked about their favorite thing at school, many students referred to active times of the day. Several students referenced $\mathrm{PE}$ as the thing they like most about school. For example, one 2-B student said, "What I like about school is PE because it gets me ready to learn and it gives me a little exercise and we get to do fun things and like climb up ropes and stuff." Others referenced recess, like this K-A student who said, "I like recess because there's lots of slides," and a 2-C student who said, "I like playing at recess with my friends." While many students also referenced other subjects or times of the day - there was a distinct theme associated with movement-based school experiences as their favorite thing in school.

More PA in school. The students were able to identify that they spent the majority of the school day sitting, not moving, and requested more PA throughout the school day. When asked when they get to move at school, the students in this study cited PE, recess, and music as times during the school day that they experienced the most PA. One K-A student explained, "I can think of the only time I get exercise [at school] is at recess," and a 2-C student said, "When we play outside at recess; like basketball, football, anything like that. One time...we did a GoNoodle once in art." While most of their responses echoed the students quoted above, some students did identify movement in the classroom as a time they are physically active at school. A 1-B student told us, "Sometimes in the classroom we play heads up seven up, and that's the time when people go around and tap people's thumbs and some of us get to stand up."

The students in this study overwhelmingly requested more PA in school, and they were able to identify specific times during the school day where this PA could take place. Frequent references to math, writing, and reading were specific subjects they identified when asked if there were certain times of the day that they thought they could move more. One 1-A student replied, “Test! You never move when we do tests!" with all of his peers agreeing with his statement. A 2-A student, who was clearly a fan of moving more throughout the day, responded rather enthusiastically, "At the starting of the day, in the middle of the day, and at the end - and sometimes in between." In summary, all of the students in this study at some point or another stated their support for additional PA throughout the day.

\section{Stakeholder: Teachers}

Three themes emerged across the data collected from teachers in this study: favorable perceptions of PA in the classroom, barriers associated with PA during school, and a desire for support associated with integrating PA in their classrooms.

Favorable perceptions of PA in the classroom. When asked about movement in the classroom and the benefits of PA for students, all of the teachers in this study responded favorably and supported movement in their classrooms. Most of the teachers referred specifically to PA benefitting students' learning and focus. For example, Candice said, "I believe that movement is crucial for kids' learning," and Meghan said, "...I've realized that you have to have that movement in order for them to retain the information.” Along with learning, some referred specifically to movement and its connection with concentration and behavior. Joanne explained:

If they are not getting enough physical activity you are going to see it in the classroom. I mean little kids have energy and if they are not finding an outlet for their energy then they are going to find it when they need to concentrate and need to focus.

With respect to behavior, Trish said, "I will tell you what, when you are moving around a lot you [the teacher] don't have the discipline problems [with students]. You just don't."

Two teachers in this study had even taken the step of including flexible seating in their classrooms because of their beliefs surrounding the importance of movement for students. Nikki explained her decision to pursue flexible seating, which in her case included exercise balls, bouncy bands (on bottom of chair), and wobble chairs, by saying:

I feel it [movement] is very important. This is my first year that I started the flexible seating classroom. Last year I had noticed a lot of children either didn't look comfortable in their regular desk and chair, or they were either standing, they were kneeling at their desk. Their bodies were moving or kids were sitting in like really strange positions with their feet in the air. So, it was kind of obvious to me that they wanted to move or 
they needed that and the regular chair wasn't giving them that.

The other teacher who had moved to flexible seating iterated a similar rationale, and while it worked for these teachers, some of the teachers in the study mentioned that they could not "handle" having the kids bouncing around in their classes.

Barriers. Two main barriers were identified by all of the teachers in this study - lack of time and lack of space. While other barriers, such as loss of control, were mentioned by a couple of teachers, it was not a prominent theme. When considering time, Joanne said, "We have a lot to teach and not a lot of time." Time as a barrier was also mentioned by Leanne when she said, "I think the biggest challenges with this grade is just wasting time in a transition. That is the biggest thing. We are so jammed packed which is good and bad with requirements of what we need to do academically." These teachers seemed to understand the importance of movement, but struggled with how to balance all of their responsibility in the classroom and managing their students. Candice said, "Every seven to eight minutes the kids should be up and moving, and that's not always feasible depending on the population of students you have."

With respect to space, most of the teachers acknowledged this as a challenge. For example, Nikki explained:

Classrooms aren't generally very big and open. Especially with all the tables and stuff it is kind of hard when we are doing the GoNoodle things where there is a lot of movement. You want to be moving but then they are knocking into each other or the tables. I think that has been a hard challenge.

Similarly, Candice acknowledged the challenge of space with the number of students in her class, "As we are adding more and more students to a classroom, it is not putting kids first and it just isn't because just the physical space that we each need to learn and be curious is limiting." Makaylin discussed safety with respect to space when she explained challenges of integrating movement, "Just the type of class, and if it is safe you know for it [movement]. And then room, in here when you have 25 kiddos and the ability to have them all do the same thing." Similar concerns with respect to space to move in the classroom were echoed by the other teachers involved in this study.

Support needed. Given their overall support for PA in their classrooms, it was not surprising to hear them ask for support associated with their ability to integrate more movement into their classrooms. While there was some diversity in their requests, the majority of the participants requested resources and management tools.

When considering resources, many of the teachers in this study were simply looking for ideas. Joanne explained this thoroughly when she detailed her thoughts on resources:

Teachers have so many different moving parts that they are dealing with at any given time that sometimes the next new idea just kind of gets put to the back burner...behind report cards and talking to the parents and doing all these other things that need to be done.
While her discussion could also support the time challenge, for her it comes down to being provided with additional resources - and the majority of her peers also mentioned this as something they needed in order to create a more active classroom.

The teachers did also mention the collaborative support of their PE teacher, with Kayla saying, "Our PE teacher sometimes she will send us information but for the most part we find it through different blogs or stuff what you can do." Meghan explained her desire to work more with the PE teacher when she said, "Collaboration with the PE department and stuff. So, I think that would be really useful if she could come in and like maybe observe and give me ideas of how I could incorporate physical activity."

Management tools were also something that these teachers seemed to really want in order to create more physically active classrooms. For example, Nikki explained, “...figuring out how I can more efficiently incorporate it [movement] into my curriculum and daily activities. And how to give the kids a little more movement even as they are working." Their discussions around loss of control when students are physically active in their classrooms also support this subtheme. For example, Joanne outlined her biggest challenge:

In my opinion one of the biggest challenges is the control you have on your class because I think a lot of teachers hesitate away because they have such a tentative control at any given time. It is really hard if you don't have control to bring your students back after physical movement.

Overall, the only supports these teachers perceived needing in order to make their classrooms more physically active environments were the need for more resources and more information on how to successfully manage PA in the classroom.

\section{Stakeholder: Principal}

The themes aligned with the principal included being supportive of PA in her school and her perceived barriers associated with movement integration.

Support for PA in school. The principal interviewed in this study noted that she believed PA is "vital" for students' learning at school saying, "I think it [PA] is vital. It is a vital part of the day and understanding how kids operate and making sure they move and kids learn better." She also described a very active school culture for the students in this school, "From the moment they [students] come to school they are on the playground moving. We encourage them - if they are in the hall, we are like 'go outside."”

With respect to encouraging her staff to incorporate more movement, Cathie responded:

Encouraging people not to take away recess. Encouraging brain breaks. [PE teacher] and I have talked a lot, and probably not - I haven't given her a lot of time, but she has had time every year at staff meetings to, well five minutes, something [to advocate for PA]. 
While she was clearly very supportive of her staff providing more PA for students in the school, Cathie was not sure if she had ever explicitly communicated this to them:

I am trying to decide if I have ever really flat out said it. Um, we have talked a lot about not taking recess away. My philosophy is not taking recess away. But I don't know that I have ever really just made that statement to people.

Although she reflected about her communication to teachers, it was clear that Cathie was very supportive of PA in her school. She proudly referred to teachers who had pursued flexible seating for their students and even one who moved his desk out of the classroom to make more room for students (and potentially movement).

Barriers to movement integration. When asked about challenges teachers faced when considering including more PA, Cathie cited lack of time and knowledge of movement integration techniques. She explained this by saying:

I think the biggest issue is time. Always. It is like the four-letter bad word. Time. And then teachers - like how do I incorporate it well. So, I would say probably most people do brain breaks and they haven't necessarily integrated it...to really enhance the curriculum. The brain breaks are easy...but it is a lot harder and it takes more time to be more thoughtful about how you truly are incorporating movement into your core content and how to make - have the movement help students learn the content.

Interestingly (and, a point that contradicted the teachers' perceived barriers), she initially said that space was an issue, but continued to discuss that they were fortunate at this school because, “...we have big classrooms. I look at our sister school, and their classrooms are very small. So, space and the environment is huge."

\section{Limitations}

This study includes limitations that merit further discussion. First, the findings from this study may not be generalizable to other schools due to the fact that all participants worked in/attended the same school. However, all participants being from the same school also contributes to the uniqueness of this study since schools are context-specific and multiple stakeholders within them are collaborating to achieve common goals. Additionally, the school had a relatively low percentage of students qualifying for free and reduced lunch, therefore it is necessary for others to contextualize these results accordingly. Further, the nature of focus group interviews lends itself to the potential of some social influence that biased student responses. Nevertheless, the students in this study were encouraged to speak individually and given opportunities to express differing viewpoints and disagreement during the focus group interviews.

\section{DISCUSSION}

The purpose of this study was to explore the perceptions of multiple stakeholders when it comes to PA promotion in the school environment. Specifically, we considered perspectives of students, teachers, and the principal, which contribute to the strength of the study. Considering the input from a variety of stakeholders within a school is important given how contextually diverse schools can be. While PA was consistently highly-regarded across all stakeholder groups, some supports and challenges for increasing PA during school were identified by the teachers and the principal. Furthermore, students tended to focus more on different aspects of PA participation (e.g., health benefits, enjoyment) at school than the other stakeholders in this study. To the authors' knowledge, this study is the first to examine the unique perspectives surrounding school PA from three different groups of key stakeholders within one school.

\section{Stakeholder: Students}

Although students endorsed teachers' beliefs of the benefits of PA for learning and focus, they tended to highlight the opinion that movement and exercise provided them with physical health benefits such as being good for their heart and making them strong. This supports previous findings of primary school children's perceptions of PA at school, specifically in the classroom (McMullen et al., 2019). The emphasis students placed on the physical vs. cognitive benefits of PA also differed from the principal's focus on PA at school as a means of improving student learning and behavior. Along with discussing health benefits reaped from PA participation, most of the students agreed with recent research by reporting that they enjoy engaging in PA in the classroom (Martin and Murtagh 2017; McMullen et al., 2019). Student enjoyment of movement opportunities at school is thus another important factor when considering the sustainability of schoolwide PA programs, as teachers have reported student enjoyment and request for physical activities as reasons for continued classroom movement integration (Goh, Hannon, Webster, and Podlog, 2017; McMullen et al., 2016).

\section{Stakeholder: Teachers}

Teachers in this study emphasized the need for specific ideas, resources, and management tools to support PA integration in the classroom environment. Academic performance is not negatively impacted when PA replaces academic time at school (Rasmussen and Laumann, 2013) and research has demonstrated improved academic achievement among young children as a result of PA integrated into academic lessons (Shoval, Sharir, Arnon, and Tenenbaum, 2018). Therefore, incorporating PA into classroom instruction likely benefits multiple groups of stakeholders and specifically addresses the lack of time barrier commonly reported by teachers in this study and others (McMullen, Kulinna, and Cothran, 2014; McMullen et al., 2016; Stylianou et al., 2016). Other ways to enhance children's PA opportunities in the classroom without taking time away from instructional practices are for teachers to direct frequent transitions (e.g., have students move from their desks to the carpet) and capitalize on the physical environment, such as by spreading 
out furniture and materials to facilitate autonomous movement or providing equipment like exercise ball chairs (Ellis et al., 2018; Russ et al., 2017).

\section{Stakeholder: Principal}

In contrast to what teachers articulated about space issues, the principal seemed to conclude that small classrooms were not a concern at their school. Although the principal in this study sometimes reminds teachers to do brain breaks in class, she admitted this topic has not been a priority in her school. While the research on principals' perceptions of PA in schools is limited, they have reported mostly political and economic barriers to increasing PA (Allison et al., 2016; Brown and Elliott, 2015). Since most studies examining stakeholder perspectives to-date have centered on teachers, and teachers have indicated that administrator support is essential for school movement integration (McMullen et al., 2014; Routen et al., 2018), additional research should continue to seek to learn more about administrator and senior management perceptions so that impactful school-based PA programs can be sustained.

\section{Similarities in Stakeholder Perceptions}

The stakeholders at this school held positive attitudes toward PA promotion during school. Overall, teachers and the principal agreed that support for PA promotion is essential and that lack of time is a significant barrier to promoting PA in the classroom. These are perceptions echoed from previous research (McMullen et al., 2016; Stylianou et al., 2016). Like teachers and students, the principal also expressed her belief that PA at school is advantageous for student learning and behavior. Indeed, evidence has supported a positive association between classroom PA and elementary student behavior, including time spent on-task (Howie, Beets, and Pate, 2014; Szabo-Reed et al., 2017). Further, the teachers' and the principal in this study both valued the connection between PA in the classroom and academic-related outcomes, which is consistent with previous research (Brown and Elliott, 2015). When considering the importance of stakeholder education and buy-in (Goc Karp et al., 2014) and specifically the work of trained PALs like the one working in this study's school (Centeio et al., 2014a; Webster, Beets, Weaver, Vazou and Russ, 2015), the results of the present study are encouraging given the shared support expressed by stakeholders.

The relationships between stakeholder groups' perceptions toward PA at their school correspond with the interdependent levels represented by an ecological systems model of human development (Bronfenbrenner, 1977; Bronfenbrenner and Morris, 1998). For instance, if healthy student behavior, such as engagement in PA, is thought of as the focus of a school health program (Carson et al., 2014), the perspectives of students regarding such behavior reflect the intrapersonal level of a social ecological model (SEM; Emmons, 2000) and inform the success of that behavior or program outcome (Morse and Allensworth, 2015). The perspectives of teachers and school administrators, then, mirror the interpersonal level of the SEM, with the administrator's role overlapping into even higher contextual levels of influence on the health behavior such as the organizational and policy levels (Carson et al., 2014; Emmons, 2000). Like the SEM posits, CSPAP research has suggested that improving student PA necessitates support from multiple levels and a variety of stakeholders in each contextually-unique school setting (Hunt and Metzler, 2017).

\section{CONCLUSIONS}

Despite several similarities found in this study between stakeholder perceptions surrounding school PA, some key differences were discovered. One of the largest discrepancies between stakeholder perceptions was the focus on cognitive/behavioral vs. physical benefits of PA. Specifically, teachers and the school principal tended to describe the primary benefits of integrating PA at school as being improved student learning, focus, and behavior. Conversely, the students tended to focus on the physical health benefits of being active (e.g., getting stronger). Notably, all three stakeholder groups provided support for PA promotion in school; which suggests that the school environment is an appropriate site for public health efforts to increase PA in children. When trying to increase primary school teacher and administrator buy-in and support, advocates could emphasize student enjoyment, the potential academic and behavioral benefits of schoolwide PA over the health benefits, and the environmental factors that make the school an ideal site for PA promotion. This study is one of few studies to consider the unique perspectives of multiple stakeholder groups and results can lend themselves to informing the successful development, implementation, and maintenance of PA promotion in the school environment.

\section{REFERENCES}

Abbott, R. A., Straker, L. M. and Erik Mathiassen, S. (2013). Patterning of children's sedentary time at and away from school. Obesity, 21, E131-E133. https://doi.org/10.1002/ oby. 20127

Allison, K. R., Vu-Nguyen, K., Ng, B., Schoueri-Mychasiw, N., Dwyer, J. J., Manson, H., ... Robertson, J. (2016). Evaluation of daily physical activity (DPA) policy implementation in Ontario: Surveys of elementary school administrators and teachers. BMC Public Health, 16, 746. https://doi.org/10.1186/s12889-016-3423-0

Bronfenbrenner, U. (1977). Toward an experimental ecology of human development. American Psychologist, 32, 513-531. https://doi.org/10.1037/0003-066X.32.7.513

Bronfenbrenner, U. and Morris, P. A. (1998). The ecology of developmental processes. In W. Damon and R. M. Lerner (Eds.), Handbook of child psychology: Theoretical models of human development (pp. 993-1028). Hoboken, NI: John Wiley.

Brown, K. M. and Elliott, S. J. (2015). “It’s not as easy as just saying 20 minutes a day": Exploring teacher and principal experiences implementing a provincial physical activity policy. Universal Journal of Public Health, 3, 71-83. https://doi.org/10.13189/ujph.2015.030204 
Carson, R. L., Castelli, D. M., Beighle, A. and Erwin, H. (2014). School-based physical activity promotion: A conceptual framework for research and practice. Childhood Obesity, 10, 100-106. https://doi.org/10.1089/chi.2013.0134

Centeio, E. E., Erwin, H. and Castelli, D. M. (2014a). Chapter 4 Comprehensive school physical activity programs: Characteristics of trained teachers. Journal of Teaching in Physical Education, 33, 492-510. https://doi.org/10.1123/ jtpe.2014-0066

Centeio, E. E., McCaughtry, N., Gutuskey, L., Garn, A. C., Somers, C., Shen, B., ... Kulik, N. L. (2014b). Chapter 8 Physical activity change through comprehensive school physical activity programs in urban elementary schools. Journal of Teaching in Physical Education, 33, 573-591. https://doi.org/10.1123/jtpe.2014-0067

Centers for Disease Control and Prevention [CDC] (2017). Increasing physical education and physical activity: A framework for schools. CDC: Atlanta, GA.

Corbin, J. and Strauss, A. (2008). Basics of Qualitative Research: Techniques and Procedures for Developing Grounded Theory (3rd ed.). Thousand Oaks, CA: Sage. https://doi.org/10.4135/9781452230153

Creswell, J.W. (2013). Qualitative Inquiry \& Research Design. Choosing Among Five Approaches ( $3^{\text {rd }}$ ed). Sage Publications Inc: Thousand Oaks, CA.

Dinkel, D., Schaffer, C., Snyder, K. and Lee, J. M. (2017). They just need to move: Teachers' perception of classroom physical activity breaks. Teaching and Teacher Education, 63, 186-195. https://doi.org/10.1016/j.tate.2016.12.020

Ellis, Y. G., Cliff, D. P. and Okely, A. D. (2018). Childcare educators' perceptions of and solutions to reducing sitting time in young children: A qualitative study. Early Childhood Education Journal, 46, 377-385. https://doi.org/10.1007/ s10643-017-0867-5

Emmons, K. (2000). Health behaviours in a social context. In L. Berkman and I. Kawachi (Eds.), Social epidemiology (pp. 242-266). New York, NY: Oxford University Press.

Finn, K. E. and McInnis, K. J. (2014). Teachers' and students' perceptions of the active science curriculum: Incorporating physical activity into middle school science classrooms. The Physical Educator, 71, 234-253.

Goc Karp, G., Scruggs, P. W., Brown, H. and Kelder, S. H. (2014). Chapter 10 Implications for comprehensive school physical activity program implementation. Journal of Teaching in Physical Education, 33, 611-623. https://doi.org/10.1123/ jtpe.2014-0116

Goh, T. L., Hannon, J. C., Webster, C. A. and Podlog, L. (2017). Classroom teachers' experiences implementing a movement integration program: Barriers, facilitators, and continuance. Teaching and Teacher Education, 66, 88-95. https://doi.org/10.1016/j.tate.2017.04.003

Hnatiuk, J. A., Salmon, J., Hinkley, T., Okely, A. D. and Trost, S. (2014). A review of preschool children's physical activity and sedentary time using objective measures. American Journal of Preventive Medicine, 47, 487-497. https://doi.org/10.1016/j.amepre.2014.05.042
Howie, E. K., Beets, M. W. and Pate, R. R. (2014). Acute classroom exercise breaks improve on-task behavior in 4 th and 5th grade students: A dose-response. Mental Health and Physical Activity, 7, 65-71. https://doi.org/10.1016/ j.mhpa.2014.05.002

Hunt, K. and Metzler, M. (2017). Adoption of comprehensive school physical activity programs: A literature review. Physical Educator, 74(2), . https://doi.org/10.18666/TPE2017-V74-I2-7167

Institute of Medicine. (2013). Educating the student body: Taking physical activity and physical education to school. Washington, DC: The National Academies Press.

Jones, E. M., Taliaferro, A. R., Elliott, E. M., Bulger, S. M., Kristjansson, A. L., Neal, W. and Allar, I. (2014). Chapter 3 Feasibility study of comprehensive school physical activity programs in Appalachian communities: The McDowell CHOICES project. Journal of Teaching in Physical Education, 33, 467-491. https://doi.org/10.1123/jtpe.2014-0065

Kvale and Brinkmann, 2009. Interviews. Learning the craft of qualitative research interviewing. ( $\left.2^{\text {nd }} \mathrm{ed}\right)$. Thousand Oaks, CA: Sage.

$\mathrm{Lu}, \mathrm{C}$. and Montague, B. (2016). Move to learn, learn to move: Prioritizing physical activity in early childhood education programming. Early Childhood Education Journal, 44, 409417. https://doi.org/10.1007/s10643-015-0730-5

Lynch, T. (2015). Health and physical education (HPE): Implementation in primary schools. International Journal of Educational Research, 70, 88-100. https://doi.org/10.1016/ j.ijer.2015.02.003

Määttä, S., Ray, C., Roos, G. and Roos, E. (2016). Applying a socioecological model to understand preschool children's sedentary behaviors from the viewpoints of parents and preschool personnel. Early Childhood Education Journal, 44, 491-502. https://doi.org/10.1007/s10643-015-0737-y

Martin, R. and Murtagh, E. M. (2017). Teachers' and students' perspectives of participating in the 'Active Classrooms' movement integration programme. Teaching and Teacher Education, 63, 218-230. https://doi.org/10.1016/j.tate. 2017.01.002

McMullen, J. M., MacPhail, A. and Dillon, M. (2019). “I want to do it all day!”-Students' experiences of classroom movement integration. International Journal of Educational Research, 94, 52-65. https://doi.org/10.1016/j.ijer.2018. 11.014

McMullen, J. M., Martin, R., Jones, J. and Murtagh, E. M. (2016). Moving to learn Ireland - Classroom teachers' experiences of movement integration. Teaching and Teacher Education, 60, 321-330. https://doi.org/10.1016/j.tate.2016.08.019

McMullen, J. M., Ní Chróinín, D., Tammelin, T., Pogorzelska, M. and van der Mars, H. (2015). International approaches to whole-of-school physical activity promotion. Quest, 67, 384-399. https://doi.org/10.1080/00336297.2015.1082920

McMullen, J., Kulinna, P. and Cothran, D. (2014). Chapter 5 Physical activity opportunities during the school day: Classroom teachers' perceptions of using activity breaks in the classroom. Journal of Teaching in Physical Education, 33, 511-527. https://doi.org/10.1123/jtpe.2014-0062 
Michael, R. D., Webster, C.A., Egan, C., Nilges, L., Ali, B., Johnson, R. and Carson, R. L. (2019). Facilitators and barriers to movement integration in elementary classrooms: A systematic review. Research Quarterly for Exercise and Sport, 90, 151-162. https://doi.org/10.1080/02701367.2019.1571675

Morse, L. L. and Allensworth, D. D. (2015). Placing students at the center: The Whole School, Whole Community, Whole Child Model. Journal of School Health, 85, 785-794. https://doi.org/10.1111/josh.12313

National Physical Activity Plan Alliance. (2016). U.S. National Physical Activity Plan. Retrieved from http://physical activityplan.org/docs/2016NPAP_Finalforwebsite.pdf

Phelps, A., Calvert, H. G., Hwang, J., Glowacki, E., Carson, R. L. and Castelli, D. (2018). Environmental Characteristics Related to Comprehensive School Physical Activity Program Implementation. European Journal of Environment and Public Health, 2(2), 07. https://doi.org/10.20897/ ejeph/92007

Rasmussen, M. and Laumann, K. (2013). The academic and psychological benefits of exercise in healthy children and adolescents. European Journal of Psychology of Education, 28, 945-962. https://doi.org/10.1007/s10212-012-0148-z

Riley, N., Lubans, D., Holmes, K., Hansen, V., Gore, J. and Morgan, P. (2017). Movement-based mathematics: Enjoyment and engagement without compromising learning through the EASY minds program. EURASIA Journal of Mathematics Science and Technology Education, 13, 1653-1673. https://doi.org/10.12973/eurasia.2017. 00690a

Routen, A. C., Johnston, J. P., Glazebrook, C. and Sherar, L. B. (2018). Teacher perceptions on the delivery and implementation of movement integration strategies: The CLASS PAL (Physically Active Learning) Programme. International Journal of Educational Research, 88, 48-59. https://doi.org/10.1016/j.ijer.2018.01.003

Russ, L. B., Webster, C. A., Beets, M. W., Egan, C., Weaver, R. G., Harvey, R. and Phillips, D. S. (2017). Development of the System for Observing Student Movement in Academic Routines and Transitions (SOSMART). Health Education \& Behavior, 44, 304-315. https://doi.org/10.1177/109019811 6657778

Shoval, E., Sharir, T., Arnon, M. and Tenenbaum, G. (2018). The effect of integrating movement into the learning environment of kindergarten children on their academic achievements. Early Childhood Education Journal, 46, 355364. https://doi.org/10.1007/s10643-017-0870-x
Stylianou, M., Kulinna, P. H. and Naiman, T. (2016). “... because there's nobody who can just sit that long”: Teacher perceptions of classroom-based physical activity and related management issues. European Physical Education Review, 22, 390-408. https://doi.org/10.1177/1356336X 15613968

Sullivan, R. A., Kuzel, A. H., Vaandering, M. E. and Chen, W. (2017). The association of physical activity and academic behavior: A systematic review. Journal of School Health, 87, 388-398. https://doi.org/10.1111/josh.12502

Szabo-Reed, A. N., Willis, E. A., Lee, J., Hillman, C. H., Washburn, R. A. and Donnelly, J. E. (2017). Impact of three years of classroom physical activity bouts on time-on-task behavior. Medicine and Science in Sports and Exercise, 49, 2343-2350.

https://doi.org/10.1249/MSS.0000000000001346

Todd, C., Christian, D., Davies, H., Rance, J., Stratton, G., Rapport, F. and Brophy, S. (2015). Headteachers' prior beliefs on child health and their engagement in school based health interventions: A qualitative study. BMC Research Notes, 8, 161. https://doi.org/10.1186/s13104015-1091-2

U.S. Department of Health and Human Services (USDHHS; 2018). Physical Activity Guidelines for Americans, 2nd edition. USDHHS: Washington, DC.

van den Berg, V., Salimi, R., de Groot, R. H. M., Jolles, J., Chinapaw, M. J. M. and Singh, A. S. (2017). "It's a battle ... You want to do it, but how will you get it done?”: Teachers' and principals' perceptions of implementing additional physical activity in school for academic performance. International Journal of Environmental Research and Public Health, 14, 1160, https://doi.org/10.3390/ijerph14101160

Webster, C. A., Beets, M., Weaver, R. G., Vazou, S. and Russ, L. (2015). Rethinking recommendations for implementing comprehensive school physical activity programs: A partnership model, Quest, 67, 185-202. https://doi.org/10.1080/00336297.2015.1017588

Webster, C. A., Zarrett, N., Skiles-Cook, B., Egan, C. and Nesbitt, D. (2017). Movement integration in elementary classrooms: Teacher perceptions and implications for program planning. Evaluation and Program Planning, 61, 134-143.

https://doi.org/10.1016/j.evalprogplan.2016.12.011

Weissman, P. and Hendrick, J. (2013). The whole child: Developmental education for the early years (10 $10^{\text {th }}$ ed.). Boston: Pearson.

World Health Organization (WHO). (2012). Population-based approaches to childhood obesity prevention. Retrieved from http://www.who.int/dietphysicalactivity/childhood/ WHO_new_childhoodobesity_PREVENTION_27nov_HR_PR INT_OK.pdf 